\title{
Breves reflexiones sobre la reforma constitucional al sistema de pensiones
}

\author{
Víctor Julio Usme Perea*
}

Fecha de recibido: marzo 22 de 2006

Fecha de aprobación: mayo 24 de 2006

\section{RESUMEN}

El pago excesivo de las pensiones a cargo del Estado que beneficiaba a un limitado sector de la sociedad venía ocasionando una preocupante crisis fiscal. Ante esa situación el gobierno del presidente Álvaro Uribe decide impulsar un acto reformatorio de la constitución que a futuro garantizará la sostenibilidad financiera, la eliminación de los regímenes especiales, el tope mínimo y máximo del monto de la prestación, entre otros temas. A partir de un análisis jurídico y social el texto aborda el acto legislativo 01 del 22 de julio de 2005, que transformó el sistema general de pensiones y que tiene como propósito lograr estabilidad en el régimen de pensiones.

\section{PALABRAS CLAVE}

Reforma, pensión, seguridad social, régimen de transición, derechos adquiridos.

\begin{abstract}
The excessive payment of pensions in charge of the state that are benefited to limited sector of society, provoked a worrying fiscal crisis. In face to this situation the President Alvaro Uribe's government decided to impel a reformatory act of the constitution that in the future would guarantee the financial sustaining, the elimination of special regulations, and the minimum and maximum limit of pensive amount, among other subjects. From a juridical and social analysis the article approaches to the legislative act 01 of July 22 of 2005 that transformed the General System of pension and that has as purpose to get the stability of the pension regime.
\end{abstract}

\section{KEY WORDS}

Reform, pension, social security, transition regime, acquired rights. 


\section{Introducción}

La grave situación fiscal que ha generado el reconocimiento y pago excesivo de las pensiones a cargo del Estado puso en alerta al legislativo y al ejecutivo. Ante tan oscuro panorama se evidencian varios intentos para que a través de la Leyes -797 y 860 de 2003, e incluso del referendo, se lograra transformar el sistema pensional, intentos que a la postre resultaron frustrados por las declaraciones de inexequibilidad de la Corte Constitucional.

Por ello, se estimó, lastimosamente, que el último sendero que le quedaba al país para tratar de sanear las finanzas públicas, por encontrarse tan comprometidas con el régimen pensional, no era otro que el de una reforma por medio de un acto legislativo para que quedara incorporada dentro de la Constitución Nacional.

Nace, entonces, el Acto Legislativo 01 del 22 de julio de 2005, por el cual se adiciona el artículo 48 de la Constitución Política de 1991, y se fija un andamiaje pensional basado, entre otros, en la sostenibilidad financiera; exclusividad del Sistema General de Pensiones respecto de requisitos y beneficios; eliminación de los regímenes especiales, exceptuados y la mesada catorce; tope mínimo y máximo del monto de la prestación; prohibición de establecerse en pactos, convenciones colectivas de trabajo, laudos o acto jurídico alguno, condiciones pensionales diferentes a las establecidas en la leyes del Sistema General de Pensiones (los pactados perderán vigencia el 31 de julio de 2010), así como un régimen de transición.

Adentrémonos, pues, en el recorrido por algunos de los temas de la tan anhelada reforma pensional.

\section{Necesidad de la reforma}

Ante todo, conviene destacar que, para desarrollar el presente capítulo, se tendrá en consideración la exposición de motivos del acto legislativo como fuente fidedigna que refleja claramente la difícil situación de la cual adolece el sistema pensional en Colombia, pues a no dudarlo, aquélla constituye el alma y el querer del constituyente derivado o secundario para paliar dicha crisis.

Para tal efecto, sólo tomaremos en cuenta los dos siguientes tópicos, sin soslayar la existencia de otros tantos factores determinantes.

\subsection{Problemas financieros}

Dentro de los muchos desaciertos que se pueden identificar como generadores de las dificultades en la financiación del pasivo pensional, se tienen: (i) la aplicación de bajas cotizaciones; (ii) inversiones de las reservas del Seguro Social; (iii) beneficios exagerados; (iv) falta de equivalencia entre las cotizaciones y las prestaciones o beneficios percibidos; (v) los económicos a consecuencia del desempleo; (vi) los de orden demográfico referidos a la disminución en las tasas de natalidad y mortalidad en relación con el aumento de las esperanzas de vida, toda vez que, por ejemplo, antes de la expedición de la Ley 100 de 1993, una pensión se pagaba por espacio de 15 años que, desde luego, era la base para el cálculo de las cotizaciones, mientras que actualmente dicha expectativa de pago está en 26 años, incluyendo el disfrute de la pensión por parte de los beneficiarios, con el agravante de que tiende a aumentarse con el correlativo costo adicional que ello acarrea; (vii) no cotizan todos los trabajadores; y (viii) evasión y elusión de las cotizaciones.

Algo más complejo se presenta con el respaldo que por el funcionamiento del fondo se requiere de los afiliados cotizantes para subvencionar las prestaciones de los pensionados -maduración del régimenEs menester recordar que en 1980 existían 2 pensionados por cada 100 afiliados cotizantes, para 1993, 10 
pensionados por cada 100 afiliados cotizantes, y en el año 2002, 21 pensionados por cada 100 afiliados cotizantes.

Las circunstancias anteriores acrecentaron el desequilibrio existente entre el monto de las cotizaciones y los beneficios que el sistema ofrece, lo que condujo inexorablemente a utilizar los recursos de la reserva del Instituto de Seguros Sociales, afectando, de paso, el presupuesto general de la Nación en el orden del 3.3\% del PIB en el 2000 ( 5.1 billones) y del $4.6 \%$ del PIB para el 2004 (8.2 billones).

El entorno no se muestra más consolador, si se tiene en cuenta que antes de las reformas pensionales contenidas en las leyes 797 y 860 de 2003, el déficit pensional ascendía al 207\% del PIB del 2000, en un horizonte de 50 años, el cual disminuyó, con posterioridad a dichas regulaciones, a 170,2\% del PIB en el mismo horizonte.

La siguiente gráfica ilustra el pasivo pensional como resultado del PIB en comparación con otros países.

\section{Pasivo pensional como \% del PIB}

\begin{tabular}{|l|c|}
\hline País & Pasivo Pensional \\
\hline Italia & 242 \\
\hline Francia & 216 \\
\hline Reino Unido & 193 \\
\hline Colombia & 170 \\
\hline Japón & 162 \\
\hline Uruguay & 156 \\
\hline Turquía & 146 \\
\hline Costa Rica & 97 \\
\hline Filipinas & 81 \\
\hline
\end{tabular}

Del anterior cuadro se evidencia el desequilibrio enorme que existe con relación a países con similar porcentaje del PIB como pasivo pensional, en paralelo con el nivel de cobertura de la población en edad de pensión, al punto de que en Colombia, por ejemplo, es cercano al $23 \%$ referido a personas de 60 años o más, mientras en Japón es del $\mathbf{8 8} \%$ de la población mayor de 60 años.

En el 2004 los pensionados ascendían a un millón de personas, cuatro millones en edad de pensión; los afiliados $\mathbf{1 1 . 5}$ millones, de los cuales solamente 5.2 eran cotizantes activos en comparación con los 20.5 millones de la población económicamente activa.

Además, hay que señalar que comparativamente el sistema colombiano resulta, en el monto del valor de las pensiones que se paga, más generoso que el de países industrializados y el de algunos de Latinoamérica.

\subsection{Extensión de la mesada 14}

La mesada 14 fue creada inicialmente por medio de la Ley 100 de 1993, para aquellas personas que hubieren adquirido el derecho a la pensión antes de la vigencia de la Ley 71 de 1988, esto es, el 10 de enero de 1988, y cuya finalidad esencial fue buscar una compensación por "la pérdida de la capacidad adquisitiva de sus pensiones, originada en las normas anteriores que consagraban formas de reajuste pensional inferiores al incremento del salario mínimo y a la variación del costo de vida" (Gaceta del Congreso, No. 130 del 14 de mayo de 1993, p. 6).

A pesar del claro elemento teleológico de la norma, la H. Corte Constitucional, mediante sentencia C-409 de 1994, extendió dicha mesada a todos los pensionados, lo que generó un mayor desequilibrio financiero. 
Sobre el particular, el Tribunal Constitucional, razonó así:

Para la Sala resulta evidente que al consagrarse un beneficio en favor de los pensionados por jubilación, invalidez, vejez y sobrevivientes en los términos del artículo 142 de la Ley 100 de 1993, "Cuyas pensiones se hubiesen causado y reconocido antes del 10. de enero de 1988", consistente en el pago de una mesada adicional de treinta (30) días de la pensión que les corresponde a cada uno de ellos, la cual se "cancelará con la mesada del mes de junio de cada año a partir de 1994», excluyendo a las pensiones causadas y reconocidas con posterioridad al 10. de enero de 1988, se deduce al tenor de la jurisprudencia de esta Corporación una clara violación a la prohibición de consagrar discriminaciones en el mismo sector de pensionados, otorgando privilegios para unos en detrimento de los otros, al restringir el ejercicio del derecho a la misma mesada adicional sin justificación alguna para aquellos pensionados jubilados con posterioridad al 10. de enero de 1988.

Considera la Corte que la desvalorización constante y progresiva de la moneda, que conlleva la pérdida del poder adquisitivo del salario, originado en el fenómeno inflacionario, es predicable para los efectos de decretar los reajustes anuales a todas las pensiones de jubilación sin distinción alguna. Pero ello no puede constituir fundamento de orden constitucional para privar de un beneficio pensional, como lo es la mesada adicional que se consagra en la norma materia de revisión, en favor de un sector de antiguos pensionados, excluyendo a otros que legítimamente han adquirido con posterioridad el mismo derecho pensional por haber cumplido con los requisitos legales correspondientes.

Por ello no existe razón justificada para negar la mesada adicional a estos últimos, postergándoseles su derecho a percibirla, para una fecha posterior a la que se consagra para los pensionados con anterioridad al 10. de enero de 1988.

A título informativo el costo anual de esa mesa$\mathrm{da}$, con las implicaciones del fallo, asciende a la suma de 1.1 billones de pesos.

\section{Nuevos principios constitucionales de la seguridad social}

\subsection{Sostenibilidad financiera}

A través de este postulado se le impone al Estado garantizar el mantenimiento financiero del sistema pensional, así como el de asumir el pago de la deuda pensional. En igual sentido, determina claramente el deber del legislativo de proferir leyes resguardando el equilibrio financiero del sistema, en aras de evitar que la crisis de éste se agudice.

Dichos aspectos constituyen los parámetros a tener presente por el Congreso y ejecutivo, para que de manera armónica y responsable protejan los intereses económicos, pero cuyo basamento siempre sea "el respeto por la dignidad humana" (artículo $1^{\circ}$. de la Constitución Política) y la preservación de la condición de ser humano de los dignatarios del sistema.

Otra cuestión que reviste suma importancia y cuidado es la obligación del Estado de asumir el pago de la deuda pensional, tanto pública como privada, en los eventos en que no se asegure la "sostenibilidad financiera".

Nótese de qué manera el Estado ha ido paulatinamente asumiendo unos enormes costos pensionales del sector público, que desde luego afectan en una relación directa el presupuesto de la Nación.

A título de ejemplo, veamos las cifras relacionadas en la exposición de motivos en las que se refleja que:

En la composición funcional del Presupuesto General de la Nación para el año 2004, sin incluir servicio de la deuda pública, la categoría de Protección Social concentra el $31.7 \%$ del total con $\$ 15.8$ billones, dentro de la cual se destaca la importancia del pago de pensiones corrientes, que suma $\$ 9.1$ billones, que equivalen a más del $18.2 \%$ del total de ese presupuesto, valor que 
incluye $\$ 0.7$ billones que han sido presupuestados y se requieren para que el ISS pueda atender sus obligaciones pensionales en ese año (no incluye la adición proyectada de 0.9 billones aproximadamente para este mismo propósito).

A manera de comparación, en el año 1993 los pagos de pensiones fueron de \$0.5 billones, que en ese año representaron $5.3 \%$ del presupuesto, lo cual evidencia el crecimiento de estas erogaciones con cargo al erario público, que han aumentado su participación en más de tres veces en diez años (este escenario incluye los efectos de disminución del gasto pensional de la reforma de las leyes 797 y 860). Lo anterior a pesar de que otros gastos como el de transferencias a las entidades territoriales (principalmente compuestas por salud y educación) también han tenido un crecimiento considerable, pasando de un valor equivalente al 18\% del presupuesto en 1993, a uno del $28 \%$ en el 2004.

Es decir, a los pagos corrientes de las pensiones, corresponde una porción del presupuesto que es mayor que el de cada uno de los demás sectores incluidos en el presupuesto. Debe resaltarse que con estos recursos únicamente se atiende cerca de medio millón de pensionados (Cuadro 5).

\section{Cuadro 5}

\section{Pensionados 2004 por entidad}

Número de personas

\begin{tabular}{|c|c|c|}
\hline ENTIDAD & $\begin{array}{c}\text { TOTAL } \\
\text { PENSIONADOS } \\
\text { ESTIMADOS }\end{array}$ & $\begin{array}{l}\text { PENSIÓN } \\
\text { PROMEDIO } \\
\text { (Salarios } \\
\text { Minimos) } \\
\end{array}$ \\
\hline CAJANAL & 196.935 & 2,9 \\
\hline CAJA DE RETIRO DE LA POLICIA NACIONAL & 65.346 & 2,7 \\
\hline FONDO DE PRESTACIONES SOCIALES DEL MAGISTERIO & 63.504 & 2.7 \\
\hline CAJA DE RETIRO DE LAS FUERZAS MILITARES & 32.588 & 4.7 \\
\hline MINISTERIO DE DEFENSA & 27.926 & 2,1 \\
\hline POUCIA NACIONAL & 20.457 & 3,0 \\
\hline FONDO PASINO SOCIAL DE FERROCARRILES NACIONALES & 16.577 & 2,4 \\
\hline FONCOLPUERTOS & 15.908 & 6,8 \\
\hline CAIA DE CREDITO AGRARIO INDUSTRIAL Y MINERO & 10.649 & 3,6 \\
\hline SENA & 4.203 & 3,2 \\
\hline UNINERSIDAD NACIONAL DE COLOMBIA & 4.182 & 5,9 \\
\hline MINISTERIO DE AGRICUITURA & 3.404 & 3,0 \\
\hline INCORA & 2.079 & 2.7 \\
\hline FONDO DE PREVISIÓN SOCIAL DEL CONGRESO & 1.755 & 20,7 \\
\hline OTRAS ENTIDADES & 6.747 & \\
\hline TOTAL & 472.260 & \\
\hline
\end{tabular}

Fuente: Dirección General del Presupuesto Público Nacional.

No están incluidos los pensionados del ISS porque por ahora sólo están presupuestados \$0.7 billones de la Nación para colaborar con la financiación del ISS asegurador.

Por otra parte, debe tenerse en cuenta que con un nivel similar de recursos del presupuesto de la Nación con que se pagan pensiones, se financia la educación de 8.2 millones de niños en el país, y con los recursos de salud se cofinancia la atención de 11.4 millones de afiliados al Régimen Subsidiado, es decir, con recursos similares o inferiores se presentan niveles de cobertura mucho mayores en el caso de otras actividades en las que debe concurrir la Nación para su funcionamiento, que tienen el carácter de derechos constitucionales, y que tienen un efecto importante sobre el futuro desempeño económico y social del país. 
En lo que concierne al pago de pensiones de naturaleza privada, recientemente la Corte Constitucional envió al Gobierno un mensaje de alerta para que garantice su pago oportuno.

Es así como dicha Corporación, al conocer de una tutela (T-122 de 17 de febrero de 2005) interpuesta por la Asociación Colombiana de Aviadores Jubilados de la Caja de Auxilio y Prestaciones de Acdac y otros, contra la empresa Aerovías Nacionales de Colombia S.A., Avianca, en la cual los accionantes estimaron amenazados sus derechos, tales como el pago oportuno de las pensiones de jubilación, con ocasión de la venta de la citada aerolínea a un inversionista extranjero, sostuvo:

(...) 3.5. Si bien a juicio de la Corte la acción de tutela objeto de estudio no es procedente por no darse la condición de subordinación que se requiere para que la acción de tutela contra particulares sea viable como quedó explicado, lo cierto es que en el presente caso tampoco se da el elemento de la indefensión que alegan los accionantes, pues por una parte, no está acreditado en el proceso que Avianca hasta el momento de la presentación de la acción de tutela haya incumplido con el pago de las obligaciones parafiscales a su cargo; y, por otra, la ley otorga a Caxdac los mecanismos legales ordinarios para lograr el pago de los aportes parafiscales destinados al pago de las pensiones de los aviadores en caso de incumplimiento por parte de Avianca, pues, como se señaló, el artículo 8 del Decretoley 1283 faculta a Caxdac para repetir contra la empresa incumplida por el valor de las pensiones reconocidas y pagadas.

El hecho de que Avianca S.A. se encuentre en un proceso de venta, como lo afirman los accionantes, o de reestructuración, como lo sostiene el apoderado de la parte demandada, no implica a juicio de la Corte una amenaza de los derechos a la seguridad social de los pensionados afiliados a Caxdac, pues como ya se dijo, la empresa accionada por imperativo legal se encuentra en el deber jurídico de realizar los aportes necesarios para garantizar que Caxdac realice efectivamente el pago de las pensiones de jubilación a los pilotos civiles que hubieren adquirido ese derecho y los que en el futuro lo adquieran, pues es claro que esta última entidad forma parte del Sistema de Seguridad Social que es único y, en consecuencia, es apenas un medio para que se materialice en este caso concreto la protección a que tienen derecho los trabajadores conforme a lo dispuesto por el artículo 48 de la Constitución Política y, en tal virtud, sea cual sea la negociación que adelante o pueda adelantar Avianca en el futuro, no podrá eximirse del cumplimiento de la obligación de efectuar los aportes parafiscales que con ese preciso objeto le han sido impuestos por la ley. Es más, el Estado no puede ser indiferente ni omisivo con respecto al cumplimiento de las obligaciones pensionales que deben cancelarse por conducto de Caxdac, pero con los aportes parafiscales de Avianca, sino que ha de ejercer a través de las autoridades correspondientes la facultad de inspección y vigilancia necesaria y oportuna, e imponer si es del caso las sanciones correspondientes conforme a la ley, o de no ser así, asumir la responsabilidad que le corresponda conforme al artículo 90 de la Constitución Política, en armonía con lo preceptuado por el artículo 25 de la Carta, en el cual se dispone que el trabajo gozará de la especial protección del Estado en todas sus modalidades, lo cual incluye desde luego no sólo a los trabajadores activos, sino a los trabajadores pasivos, lo que explica que el artículo 53 del Estatuto Superior en su inciso tercero preceptué que:

“[El] Estado garantiza el derecho al pago oportuno y al reajuste periódico de las pensiones legales".

De conformidad con lo expuesto, la acción de tutela interpuesta resulta improcedente, y por ello, se confirmará la sentencia revisada, no sin antes prevenir para que el Estado, a través de sus organismos correspondientes, ejerza de manera eficaz la inspección y vigilancia que les corresponde, en orden a garantizar el cumplimiento oportuno de las obligaciones legales de la Empresa Aerovías Nacionales de Colombia S.A., Avianca, para con la Caja de Auxilios y de Prestaciones de la Asociación Colombiana de Aviadores Civiles, Caxdac (...)". 
Por otra parte, la sostenibilidad NO implica que para poder cumplir con sus objetivos se pueda reducir el valor de las mesadas pensionales, criterio que deberá ser tenido en cuenta por la normatividad que se expida en el futuro, sin perjuicio, claro está, de los descuentos autorizados por la misma ley.

\subsection{Intangibilidad de las pensiones (inciso $2^{\circ}$ )}

Con la expedición de la Constitución Política de 1991, el artículo 53 instituyó la garantía estatal en el derecho al pago oportuno y al reajuste periódico de las pensiones legales. En desarrollo de dicho canon, la Ley 100 de 1993 creó la actualización de las mesadas pensionales, a $1^{\circ}$ de enero de cada anualidad, a través de la aplicación del índice de precios al consumidor causado en el año inmediatamente anterior.

De modo que, a través de este principio se prohíja que "por ningún motivo, quien tenga a su cargo el reconocimiento y pago de pensiones, bien sea el Estado a través de sus entidades nacionales o territoriales, o las empresas que tengan dicha obligación directa, así como las demás administradoras privadas del sistema, podrá incumplir el pago oportuno de las mismas incluso cuando se trate de empresas con dificultades económicas, para lo cual será necesario redimensionar el ejercicio de las facultades de inspección, vigilancia y control de las empresas estatales que en Ios diferentes sectores económicos la ejercen sobre las empresas o instituciones obligadas".

De esta manera se cobija con el manto de la constitución y se blinda en forma rigurosa el pago oportuno y completo de los derechos pensionales, para que a la postre no se vean comprometidos por situaciones de naturaleza económica a las que puedan verse avocados los pagadores, tanto públicos como privados, de la respectiva prestación social.
Finalmente, este principio guarda estrecha relación directa con el de la sostenibilidad fiscal del Estado colombiano, ya que a partir de ellos se quiere evitar que las pensiones se afecten en su valor, como aconteció, verbigracia, en Argentina y Ecuador, por lo que, frente a crisis económicas, se tendrá que acudir a la afectación de otros rubros.

\subsection{Principio de la necesaria contribución en los regímenes pensionales (inciso $3^{\circ}$ y $6^{\circ}$ )}

Constituye el pilar de todo régimen pensional contributivo, que para su funcionamiento, sostenimiento y crecimiento, requiere de los suficientes y necesarios recursos para que, a través de ellos, se atiendan las diferentes prestaciones económicas y asistenciales a las que el sistema está obligado. Por ello, en el caso de las pensiones, no sólo se debe verificar el cumplimiento de los presupuestos de edad, tiempo de servicio o semanas cotizadas o capital necesario, sino que atendiendo precisamente las cotizaciones efectuadas, la liquidación de la pensión se hará teniendo en cuenta los factores sobre los cuales se efectuaron las cotizaciones, creándose la debida equivalencia entre los aportes, determinados por el ingreso base de cotización, I.B.C., y la liquidación de la pensión -ingreso base de liquidación, I.B.L.

\subsection{Pensión mínima y máxima (Inciso $6^{\circ}$ y Parágrafo $1^{\circ}$ )}

La reforma ratifica que en Colombia no podrá existir pensión inferior al equivalente a un salario mínimo legal mensual vigente. Empero, inicialmente lo que se había previsto en el proyecto era que el mínimo vital para fines de pensión será el equivalente al salario mínimo legal vigente, redacción ésta que podría eventualmente permitir que se afectase el pago de pensiones en el total de su monto, con el argumento de que no se afectaría el mínimo vital, dado que éste corresponde al valor de un salario mínimo legal men- 
sual vigente. Aunado ello a que el concepto de mínimo vital no tiene un criterio fijo en cuanto a su contenido material, se traducía en que necesariamente serían los jueces quienes resolverían su alcance, y mientras ello ocurría las entidades obligadas a pagar pensiones podrían disminuir su valor o incluso omitir su pago, sin poner en riesgo el mínimo vital.

En relación con el monto máximo la reforma dispone que a partir del 31 de julio de 2010 no podrá adquirirse pensión cuyo valor sea superior al equivalente de 25 salarios mínimos legales mensuales vigentes, siempre que ellas se financien con cargo a recursos de naturaleza pública.

En lo que concierne a la expresión "recursos de naturaleza pública" cierta parte de la doctrina, e incluso la jurisprudencia, ha considerado que no puede ser entendida como los incorporados únicamente en el presupuesto nacional para su posterior ejecución, sino que ello es tan sólo una estimación de la cuantía. Aducen que el entendimiento de dicha expresión debe darse dentro del contexto de la parafiscalidad, tanto para los recursos con que se pagan pensiones en el régimen de prima media, como en el de ahorro individual. De acuerdo con lo anterior y con independencia de la naturaleza jurídica de la entidad que los administre, esos recursos nunca entran a formar parte del patrimonio de la entidad, y en el evento de ser pública, mucho menos de propiedad del Estado (ver la sentencia C-378/98).

\subsection{Exclusividad de la Ley en la consagración de los derechos pensionales (Parágrafo $2^{\circ}$ ) y limitación de la contratación colectiva en pensiones (Parágrafo $2^{\circ}$ y Parágrafo transitorio $3^{\circ}$ )}

Comporta que solamente a través de una ley en sentido formal se podrán fijar condiciones pensionales diferentes a las establecidas en la Ley 100 de 1993 y demás leyes que se dicten como del Sistema General de Pensiones. En consecuen- cia, se limitó el derecho fundamental a la contratación colectiva, en aspectos relativos a la fijación de las condiciones, requisitos y montos de todas las prestaciones e indemnizaciones que reconoce el Sistema General de Pensiones.

\section{Derechos adquiridos, requisitos constitucionales para adquirir el derecho a la pensión y mesada catorce}

Como es natural y obvio el Acto legislativo 1 de 2005, inciso 4, respeta los derechos adquiridos, entendidos como aquellos que hacen parte del patrimonio de una persona y que no pueden ser desconocidos por normas posteriores.

Por su parte, el inciso $3^{\circ}$ del Acto Legislativo No. 1 de 2005 creó unos requisitos de orden constitucional sin los cuales no se puede adquirir el derecho a la pensión por vejez, supuestos cuya materialización necesita concreción en leyes posteriores por ser de carácter genérico, al referirse a: "cumplir con la edad", "el tiempo de servicio", "las semanas de cotización o el capital necesario".

En cuanto a las pensiones de sobrevivientes, el mismo inciso determina que "los requisitos $y$ beneficios para adquirir el derecho a una pensión de invalidez o de sobrevivencia serán los establecidos por las leyes del Sistema General de Pensiones". El artículo 12 de la Ley 797 de 2003 instituye los requisitos para acceder a la pensión de sobrevivientes, así: si quien fallece es el pensionado, que para el presente análisis es quien nos interesa, es suficiente que los beneficiarios acrediten su calidad de tales.

Asimismo, en relación con la mesada catorce, el inciso 8 del Acto Legislativo 1 de 2005 dispone que "las personas cuyo derecho a la pensión se cause a partir de la vigencia del presente acto legislativo no podrán recibir más de 13 mesadas pensionales al año". 
Pues bien, frente a los precedentes incisos ha surgido una serie de dudas en cuanto a la mesada catorce y que radican, en rigor, en las pensiones de sobrevivientes, cuando el pensionado fallece en vigencia del acto legislativo, si los beneficiarios tienen derecho o no a la mesada catorce, las pensiones compartidas y las pensiones sanciones.

La discusión del pago de la mesada catorce, tratándose de la pensión de sobrevivientes, se centra en si este es un nuevo derecho o por el contrario es uno derivado.

Frente a este interesante tema, la Corte Suprema de Justicia, por mayoría, ha asentado que se trata de una derecho derivado, por lo que podría entenderse, entonces, que aún fallecido el pensionado después de la vigencia del acto legislativo, al beneficiario de la pensión de sobrevivientes se le deben cancelar y pagar catorce mesadas pensionales.

Creemos que los argumentos expuestos por la Sala Laboral de la Corte Suprema, expuestos en la sentencia de 14 de junio de 2005, radicación 24201, pueden servir para apoyar tal aserción:

Y ello es así porque, a pesar de que en la demanda se recabó el reconocimiento a la actora de una pensión de sobrevivientes, es dable entender que lo que en realidad ella pretendió fue la sustitución de la pensión de jubilación convencional reconocida el 10 de mayo de 1967 a su compañero, pues, como lo ha entendido la Corte en el caso de los pensionados, la pensión de sobrevivientes susceptible de transmisión no configura un derecho nuevo en favor de los causahabientes, sino un derecho derivado, una verdadera "sustitución" pensional del mismo derecho adquirido a la pensión de vejez, jubilación o invalidez causado en su favor, esto es, se trata de la transmisión de un derecho que había estado radicado en cabeza de un extrabajador, que por el hecho de la muerte pasa a sus causahabientes laborales, de suerte que, en realidad se trata del mismo derecho, por lo que exis- te una continuidad jurídica, pues conserva su misma naturaleza y características, salvo, desde luego, la del cambio de su titular.

Es indiscutible que la Ley 100 de 1993 se halla imbuida por un claro espíritu uniformador de las reglas aplicables a las pensiones y prestaciones que atienden el riesgo de vejez, pues ése es uno de los objetivos que al sistema de seguridad social integral le asigna el artículo 6 de esa célula normativa y se confirma con lo dispuesto en el artículo 11, que delimita su campo de aplicación. Pero lo anterior no significa que el generoso ámbito de esa ley se extienda a la definición de los requisitos para acceder a los derechos que, si bien guardan relación con la protección característica que brinda la seguridad contra contingencias como la vejez y la muerte, son de índole estrictamente laboral en cuanto su fuente es una convención colectiva de trabajo, como acontece con la pensión que le fue conferida al señor EPIFANIO LARA MONTAÑO, claramente surgida de lo pactado en un convenio regulador de condiciones de trabajo y que, en todo caso, no corresponde a una prestación legal, ni a una de las previstas en la Ley 100 de 1993, es decir, al «régimen solidario con prestación definida» ni al «régimen de ahorro individual con solidaridad», únicos que integran el sistema general de pensiones creado por dicha ley, como tampoco a una surgida de la aplicación del régimen de transición consagrado en el artículo 36 de la citada ley.

(...) Ya esta Sala de la Corte en relación con asuntos de contornos similares al que ahora ocupa su atención ha explicado que la Ley 100 de 1993 no eliminó instituciones jurídicas como la compatibilidad pensional, de suerte que puede ello seguir ocurriendo no obstante que el fallecimiento del causante se haya presentado estando en vigencia esa normatividad. Así lo dijo en la sentencia del 14 de febrero de 2005, radicado 22699, cuyos criterios, mutatis mutandis, resultan aplicables a la sustitución del derecho pensional discutida en el presente proceso:

(...) De otro lado, como también lo ha determinado la Corte, en el caso de los pensionados la pensión de sobrevivientes susceptible de transmisión no configura un derecho nuevo a favor de los beneficiarios, sino un derecho derivado, 
valga decir, una verdadera "sustitución pensional" del mismo derecho adquirido, que conduce a que no sea de recibo la argumentación de la censura en el sentido de haber nacido, con la muerte del señor Argumedo Hernández, un derecho diferente sujeto a nuevos condicionamientos (...).

En lo concerniente a la pensión sanción, ha sostenido la Corte Suprema de Justicia que los requisitos de causación del derecho son el tiempo laborado -diez o más años de servicios y menos de veinte-, y que el trabajador haya sido despedido sin justa causa. La edad constituye un elemento de exigibilidad.

Esto dijo la Sala Laboral de la Corte Suprema de Justicia en fallo de 13 de febrero de 2004, radicación 21902:

Por manera que el Juez de la apelación no incurrió en la infracción directa de las disposiciones de la Ley 100 de 1993 denunciadas, pues ha sido criterio pacífico de la jurisprudencia de la Corte que el derecho a la prestación jubilatoria que le fue reconocido al demandante nace con el tiempo de servicios y el despido sin justa causa del trabajador, habida consideración que la edad es únicamente una condición para su exigibilidad, como él mismo lo admite en su demanda inicial, mas en modo alguno de la configuración de ese derecho pensional.

Por lo tanto, si los presupuestos fácticos se verificaron con anterioridad a la entrada en vigor del acto legislativo 1 de 2001, esto es, 22 de julio de 2005 , la persona tiene derecho a que le reconozcan la mesada catorce, en virtud de los derechos adquiridos. Incluso, el debate se torna más complejo en el evento en que el trabajador fallezca después del 22 de julio de 2005 pero antes de cumplir con la edad requerida, en caso de causarse la pensión de sobrevivientes, ise reconoce y paga sobre la base de catorce o trece mesadas pensionales?

Por último, en lo que atañe a las pensiones a cargo del empleador, legales y extralegales, cau- sadas antes de la vigencia del acto legislativo, pero que son compartidas con el sistema pensional después de ella, le correspondería al patrono continuar con el pago de la mesada catorce, precisamente porque en cabeza del pensionado se consolidó ese derecho.

\section{Régimen de transición}

El artículo 36 de la ley 100 de 1993 creó un régimen de transición del sistema general de pensiones. Para quienes al $1^{\circ}$ de abril de 1994 hayan tenido 35 años si son mujeres o 40 años si son hombres o 15 años o más de servicios o de tiempo cotizado, a ellos se les aplicará lo establecido en la normatividad anterior a la entrada en vigor de dicho estatuto pensional, en relación con el tiempo de servicio, número de semanas cotizadas y el monto de la pensión.

Por su parte, el Acto Legislativo 01 de 2005 consagra que "el régimen de transición establecido en la Ley 100 de 1993 y demás normas que desarroIlen dicho régimen, no podrá extenderse más allá del 31 de julio de 2010; excepto para los trabajadores que estando en dicho régimen, además, tengan cotizadas al menos 750 semanas o su equivalente de tiempo de servicios a la entrada en vigencia del presente Acto Legislativo, a los cuales se les mantendrá dicho régimen hasta el año 2014. Los requisitos y beneficios pensionales para las personas cobijadas por este régimen serán los exigidos por el artículo 36 de la Ley 100 de 1993 y demás normas que desarrollen dicho régimen".

Del análisis de dichos preceptos se puede inferir a primera vista que el Acto Legislativo 01 de 2005 excluyó del régimen de transición a aquellas personas que si bien a $1^{\circ}$ de abril de 1994 tenían 35 años de edad mujeres o 40 años para los hombres, a 22 de julio de 2005, fecha de entrada en vigencia del mismo, no acrediten 750 semanas o su equivalencia de tiempo de servicios (más o 
menos 14.5 años), es decir, este grupo de personas perdieron el régimen de transición por el que se encontraban cobijados en virtud de la Ley 100 de 1993.

Pese al anterior colofón, se podría pensar que esta regulación desconoce lo que la Corte Constitucional ha denominado expectativa legítima, basada en el artículo 48 de la Carta Magna.

Sobre el particular esa Corporación, en sentencia T- 169 de 2003, sostuvo que "Una vez haya entrado en vigencia la disposición que consagra el régimen de transición, los trabajadores que cumplan con los requisitos exigidos por el mismo consolidan una situación jurídica concreta que no se les puede menoscabar. Además adquiere la calidad de derecho subjetivo que no puede ser desconocido por ningún motivo, pues le da a su titular la posibilidad del reconocimiento de la prestación en las condiciones prescritas en la normatividad anterior y la de acudir al Estado a través de la jurisdicción para que le sea protegida en caso de desconocimiento de la misma".

Por su parte el tratadista Oscar José Dueñas manifiesta que afectar un régimen de transición "es muy grave, porque no trata de simples expectativas sino de un derecho que no tiene regreso y por lo tanto es, según la teoría jurídica moderna, un derecho a algo, un derecho subjetivo, propiedad del beneficiado".

\section{Límite y tope de pensiones}

La reforma ratifica que en Colombia no podrá existir pensión inferior al equivalente a un salario mínimo legal mensual vigente. Sin embargo, inicialmente lo que se había previsto en el proyecto era que el mínimo vital para fines de pensión sería el equivalente al salario mínimo legal vigente, redacción ésta que podría eventualmente permitir que se afectase el pago de pensiones en el total de su monto, con el argumento de que no se afectaría el mínimo vital, dado que este corresponde al valor de un salario mínimo legal mensual vigente. Adicionalmente, porque el concepto de mínimo vital no tiene un criterio fijo en cuanto a su contenido material, lo que se traducía en que necesariamente serían los jueces quienes resolverían su alcance, y mientras ello ocurría las entidades obligadas a pagar pensiones podrían disminuir su valor o incluso omitir su pago sin poner en riesgo el mínimo vital.

En relación con el monto máximo dispone que a partir del 31 de julio de 2010 no podrá adquirirse pensión cuyo valor sea superior al equivalente de 25 salarios mínimos legales mensuales vigentes, siempre que ellas se financien con cargo a recursos de naturaleza pública.

El tema del tope de los 25 salarios ya se había intentado convertir en norma constitucional a través del referendo y particularmente del numeral 8 de la Ley 796/03, por medio del cual se adicionaba el artículo 187 de la Constitución Política, y que fue negado por los colombianos.

\section{Constitucionalidad del acto legislativo 1 de 2005}

Son varias las acciones de inexequibilidad que han sido presentadas para el estudio de la Corte Constitucional, ellas son: (i) archivadas, radicaciones D0005977, 0006071, 0006058, 0006011, 0006147; (ii) en curso, radicaciones 0006187, 0006057, 0006196, 0006072, 0005951, 0006209; y (ii) la sentencia C-181 de 2006, que de acuerdo con el comunicado de prensa dispuso:

12.2 Problema jurídico planteado. En el presente caso, la Corte debe determinar si en el trámite de discusión y aprobación del Acto Legislativo 01 de 2005 -por el cual se adiciona el artículo 48 de la Constitución Política- se desconocieron o no los principios de consecutividad y de identidad consagrados en la Carta Constitucional.12.3 Decisión. Primero. Declarar exequible, por los cargos analizados, el inciso décimo del artículo $1^{\circ}$ del Acto 
Legislativo 01 de 2005 -por el cual se adiciona el artículo 48 de la Constitución Política-, que dispone: "La ley establecerá un procedimiento breve para la revisión de las pensiones reconocidas con abuso del derecho o sin el cumplimiento de los requisitos establecidos en la ley o en las convenciones y laudos arbitrales válidamente celebrados. Segundo. Declárese inhibida para pronunciarse de fondo en relación con las expresiones demandadas del artículo $1^{\circ}$ del Acto Legislativo 01 de 2005, por ineptitud formal de la demanda. 12.4. Razones de la decisión. Revisado el trámite surtido por el Congreso en relación con el Acto Legislativo 01 de 2005, la Corte estableció que en el debate y aprobación del texto final del inciso décimo del artículo $1^{\circ}$ del Acto Legislativo 01 de 2005 se cumplió a cabalidad con el principio de consecutividad, toda vez que el tema de las pensiones reconocidas sin el cumplimiento de la ley o en forma fraudulenta sí fue discutido desde su inicio en el primer debate en la Comisión Primera de la Cámara de Representantes, durante la primera vuelta, hasta su inclusión en forma completa en los primeros cuatro debates de la primera vuelta y, en virtud de ello, está incluido en el texto publicado por el Gobierna Nacional, en cumplimiento del artículo 375 de la Constitución.

En virtud de lo anterior surgen una serie de interrogantes que giran en torno a si la Corte Constitucional tiene o no atribuida constitucionalmente competencia para conocer de vicios de constitucionalidad de los actos reformatorios de la Constitución distintos a los establecidos en el artículo 241.1 de la Constitución. Esto es, si la competencia se restringe a los vicios de forma o procedimiento, o si por el contrario todos los demás, Ilámense vicios materiales o de competencia, están incluidos dentro del control que corresponde a la Corte.

Ya el Tribunal Constitucional en varias sentencias ha considerado que su competencia no radica en revisar vicios de forma sino que va más allá, puesto que, si en su sentir, el acto legislativo conlleva una verdadera sustitución de la Constitución Política, su estudio implica la revisión de fondo.
Esto dijo en el fallo C-970 del 7 de octubre 2004, al estudiar la demanda de inconstitucionalidad contra el inciso segundo del artículo $4^{\circ}$ transitorio del Acto Legislativo No. 03 de 2002:

La Corte ha señalado que el poder de reforma constitucional es un poder derivado que carece de competencia para asumir el papel que corresponde al constituyente primario y no puede, por consiguiente, por la vía del procedimiento de reforma, sustituir la Constitución.

Por lo tanto, y en cuanto que esa limitación competencial se encuadra dentro de las previsiones del Título XIII de la Constitución, y específicamente en lo dispuesto en el artículo 374 de la Carta, la Corte tiene competencia para examinar los vicios en razón de la competencia del poder de reforma cuando su actuación comporte una sustitución de la Constitución.

De manera que queda claro que la Corte Constitucional si considera que el Acto Legislativo 1 de 2005 comporta una sustitución de la Constitución y puede estudiar su contendido de fondo.

Con todo, creemos que puede existir un poco de tranquilidad frente a la constitucionalidad de algunos temas tan sensibles para la comunidad, como el del régimen de transición, para que se mantenga en el acto legislativo, toda vez que en varias oportunidades la Corte Constitucional ha sostenido que no necesariamente el cambio de las condiciones establecidas en un régimen de transición es inconstitucional, pues deben primar factores de interés general.

Esto dijo en la sentencia C- 789 de 24 de septiembre 2002:

La Corte también ha sostenido que el legislador no está obligado a mantener en el tiempo las expectativas que tienen las personas conforme a las leyes vigentes en un momento determinado. Ello se debe a que, por encima de cualquier protección a estos intereses, prevalece su potestad configurativa, la cual le permite al legislador dar- 
le prioridad a otros intereses que permitan el adecuado cumplimiento de los fines del Estado Social de derecho.

Aun así, esta Corporación ha sostenido que cualquier tránsito legislativo debe consultar parámetros de justicia y equidad, y que, como toda actividad del Estado, está sujeta a los principios de razonabilidad y proporcionalidad.

En Sentencia C-147 de 1997, reiteró que para que se consolide un derecho es necesario que antes de que opere el tránsito legislativo se reúnan todas las condiciones necesarias para adquirirlo. En tal oportunidad sostuvo que "configuran derechos adquiridos las situaciones jurídicas individuales que han quedado definidas y consolidadas bajo el imperio de una ley y que, en tal virtud, se entienden incorporadas válida y definitivamente o pertenecen al patrimonio de una persona". Aclarando posteriormente que "la Constitución prohíbe el desconocimiento o modificación de las situaciones jurídicas consolidadas bajo la vigencia de una ley, con ocasión de la expedición de nuevas regulaciones legales".

La Corte en dicha sentencia continúa su análisis diferenciándolas por otra parte de las meras expectativas, que reciben una protección más precaria, aclarando el objeto y alcance de la protección constitucional a estas expectativas, diciendo que: "la ley nueva sí puede regular ciertas situaciones o hechos jurídicos que aun cuando han acaecido o se originaron bajo la vigencia de una ley no tuvieron la virtud de obtener su consolidación de manera definitiva". Así mismo, aclaró que las "expectativas pueden ser objeto de alguna consideración protectora por el legislador, con el fin de evitar que los cambios de legislación generen situaciones desiguales e inequitativas 0 de promover o de asegurar beneficios sociales para ciertos sectores de la población o, en fin, para perseguir cualquier otro objetivo de interés público o social".

Esa misma sentencia afirma que el objeto del artículo 58 de la Carta es proteger frente al tránsito legislativo aquellas situaciones particulares y concretas que se han consolidado definitivamente durante la vigencia de la ley anterior; especificando, sin embargo, que esta protección no es absoluta, y que hay determinadas condiciones bajo las cuales el interés particular en la protección de estos derechos subjetivos debe ceder frente a la utilidad pública o al interés social que motivó la expedición de la nueva ley.

En torno al punto específico objeto de decisión, en la Sentencia C-596 de 1997, la Corte determinó que las personas que habían cotizado a pensiones en los sistemas anteriores a la Ley 100 de 1993 pero que, cuando entró en vigencia el sistema de pensiones conforme al artículo 151, no habían cumplido los requisitos para acceder a la pensión conforme al sistema anterior, tenían una expectativa, no un derecho adquirido a que se les aplicara el régimen de transición consagrado en el artículo 36. Por lo tanto, conforme al criterio jurisprudencial sostenido por esta Corporación, resulta constitucionalmente admisible que el legislador imponga ciertos requisitos y restrinja con ello el acceso de las personas al régimen de transición, siempre y cuando tales restricciones sean razonables y proporcionadas. Por ese motivo la Corte en dicha oportunidad declaró exequible la expresión que condicionaba el acceso a dicho régimen de transición a que la afiliación al sistema anterior estuviera vigente cuando entró a regir el sistema de pensiones consagrado en la Ley 100 de 1993.

En tal oportunidad se refirió específicamente a la diferencia entre derechos adquiridos y expectativas de derechos en materia de pensiones. Sostuvo que puede afirmarse que se ha adquirido un derecho cuando se cumplen las condiciones consagradas en la ley para acceder a él. De lo contrario se trata de meras expectativas. Así, cuando las personas no han cumplido los requisitos para acceder a la pensión antes del tránsito legislativo, lo que dichas personas tienen son simples expectativas legítimas o expectativas de derechos, las cuales no son objeto de la protección consagrada en el artículo 58 de la Carta Política.

\section{En el aparte respectivo la Corte dijo:}

Justamente por cuanto los derechos a la seguridad social no se tienen por el simple hecho de ser persona humana, como sí sucede con los derechos fundamentales o derechos de primera generación, para ser titular de ellos es necesario 
acreditar el cumplimiento de los requisitos que la ley, de manera general, impone para adquirirlos. Cuando, en vigencia de la ley que señala tales requisitos, estos llegan a cumplirse, se habla de derecho adquirido en materia de seguridad social. Cuando, por el contrario, durante el término de vigencia de la ley que prescribe tales condiciones, la persona que aspira a la titularidad de ellos está en vía de cumplirlas, se habla de expectativa de derecho.

Las consecuencias jurídicas en uno y otro supuesto son bien distintas: Ios derechos adquiridos, al tenor del artículo 58 de la Carta Política, no pueden ser desconocidos por leyes posteriores; no así las simples expectativas de derecho.

Para el caso concreto de las personas a las que se refiere la norma demandada, esto es las personas beneficiarias del régimen de transición al que se ha hecho referencia en esta Sentencia, resulta evidente que, por cuanto ellas, al momento de entrar a regir la Ley 100 de 1993 no habían cumplido aún con los requisitos exigidos para acceder a la pensión de jubilación o de vejez por el régimen pensional al cual estuvieran afiliadas, no habían adquirido ningún derecho en tal sentido, y sólo tenían al respecto una expectativa de derecho... (Sentencia C-596 de 1997, M.P. Vladimiro Naranjo Mesa).

En este orden de ideas, el país espera que con el Acto Legislativo 1 de 2005 se superen de una vez por todas los obstáculos que han impedido tener estabilidad en el régimen pensional, y que ofrezca la calma necesaria para respirar en un ambiente de verdadera seguridad jurídica, para que, a partir de allí, se construya un sistema pensional acorde con la dignidad humana que pregona y protege nuestro Estado social y democrático de derecho. 